mental health (median: 65, 75, 75, 88, and88, respectively), while had low levels of quality in role physical, and bodily pain (median: 0 , and 22 , respectively). Patients presenting with ulcerations over tophi had worse scores on five SF-36 domains, the mental component summary (MCS) and the physical component summary (PCS) than gout patients without ulcerations [mean (SD); $P<0.05$ for all]: Bodily pain, $30.86(31.59)$ vs $35.17(33.40)$; General health, $49.46(27.01)$ vs 64.17(23.69); Vitality, 57.14(32.53) vs 72.84(26.38); Mental health, 75.4(22.43) vs 83.05(20.96); Reported health transition, 3.58(0.89) vs 3.78(1.42); MCS, $52.62(21.82)$ vs $66.65(21.44)$; PCS, 35.85(21.17) vs $46.67(23.86)$

Conclusion: Patients with ulcerations over tophi present much worse QoL compared those without ulcerations. Our study suggests that the presence of ulceration over tophi further deteriorates the QoL in gout patients.

References:

[1] Z. Huang, X. Liu, Y. Liu, et al., Clinical characteristics and risk factors of ulceration over tophi in patients with gout, Int J Rheum Dis, 22 (2019) 1052-1057.

[2] T. Fu, H. Cao, R. Yin, et al., Associated factors with functional disability and health-related quality of life in Chinese patients with gout: a case-control study, BMC Musculoskelet Disord, 18 (2017) 429.

Table 1. Clinical characteristics

\begin{tabular}{lcccc}
\hline Variable & Total $(\mathbf{n}=\mathbf{7 9})$ & $\begin{array}{c}\text { Non-ulcerations } \\
(\mathbf{n}=\mathbf{5 1})\end{array}$ & $\begin{array}{c}\text { Ulcerations } \\
(\mathbf{n}=\mathbf{2 8})\end{array}$ & $P$ value \\
\hline Male, $\mathrm{n}(\%)$ & $74(93.7)$ & $47(92.1)$ & $27(96.4)$ & 0.462 \\
Age $^{\mathrm{a}}$, mean, $\mathrm{y}$ & $54.23 \pm 14.30$ & $53.96 \pm 12.24$ & $54.71 \pm 17.69$ & 0.842 \\
Body mass index $^{\mathrm{a}}, \mathrm{kg} / \mathrm{m}^{2}$ & $24.87 \pm 3.97$ & $25.13 \pm 4.02$ & $24.40 \pm 3.91$ & 0.444 \\
Gout duration $^{\mathrm{a}} \mathrm{y}$ & $10.96 \pm 7.06$ & $10.04 \pm 6.75$ & $12.63 \pm 7.41$ & 0.119 \\
Maximum Serum uric acid, & $625.5 \pm 133.86$ & $630.9 \pm 124.23$ & $614.3 \pm 166.43$ & 0.639 \\
$\quad$ mg/dL & & & & \\
Smoking, $\mathrm{n}(\%)$ & $38(48.1)$ & $23(45.1)$ & $15(53.5)$ & 0.477 \\
Alcohol, $\mathrm{n}(\%)$ & $26(32.9)$ & $13(25.5)$ & $13(46.4)$ & 0.072 \\
Hypertension, $\mathrm{n}(\%)$ & $34(43.0)$ & $18(35.3)$ & $16(57.1)$ & 0.062 \\
Diabetes mellitus, $\mathrm{n}(\%)$ & $13(16.5)$ & $10(19.6)$ & $3(10.7)$ & 0.281 \\
Regular treatment, $\mathrm{n}(\%)$ & $3(3.8)$ & $3(5.9)$ & $0(0)$ & 0.971 \\
Glucocorticoid abuse, $\mathrm{n}(\%)$ & $18(22.8)$ & $11(21.5)$ & $7(25.0)$ & 0.173 \\
\hline
\end{tabular}

${ }^{\mathrm{a}}$ Mean (SD).

Table 2. QoL scores

\begin{tabular}{|c|c|c|c|c|}
\hline & Median (IQR) & $\begin{array}{l}\text { Non-ulcerations } \\
(n=51), \text { mean }(S D)\end{array}$ & $\begin{array}{c}\text { Ulcerations }(n=28) \text {, } \\
\text { mean }(S D)\end{array}$ & $P$ value \\
\hline Physical function ${ }^{b}$ & $50(20-80)$ & $58.62(32.17)$ & $40.89(35.97)$ & 0.095 \\
\hline Role physical $^{b}$ & $0(0-100)$ & $33.03(46.91)$ & $17.85(37.17)$ & 0.119 \\
\hline Bodily pain ${ }^{b}$ & $22(0-62)$ & $35.17(33.40)$ & $30.86(31.59)$ & 0.007 \\
\hline General health $^{b}$ & $65(40-80)$ & 64.17(23.69) & $49.46(27.01)$ & 0.014 \\
\hline Vitality $^{\mathrm{b}}$ & $75(50-95)$ & $72.84(26.38)$ & $57.14(32.53)$ & 0.023 \\
\hline Social function ${ }^{b}$ & $75(38-100)$ & $72.55(3.02)$ & $60.27(33.85)$ & 0.107 \\
\hline Role emotional ${ }^{b}$ & $88(68-96)$ & $33.98(47.37)$ & $15.43(34.45)$ & 0.135 \\
\hline Mental health ${ }^{\mathrm{b}}$ & $88(68-96)$ & $83.05(20.96)$ & $75.4(22.43)$ & 0.007 \\
\hline $\begin{array}{l}\text { Reported health } \\
\text { transition }\end{array}$ & & $3.78(1.42)$ & $3.58(0.89)$ & 0.007 \\
\hline PCS & & $46.67(23.86)$ & $35.85(21.17)$ & 0.048 \\
\hline MCS & & $66.65(21.44)$ & $52.62(21.82)$ & 0.007 \\
\hline
\end{tabular}

${ }^{\mathrm{b}}$ (range $\left.=0-100\right)$

Disclosure of Interests: None declared

DOI: 10.1136/annrheumdis-2020-eular.5104

\section{AB0932 $\quad$ FACTORS IN ACHIEVING TARGET SERUM URIC ACID LEVELS IN OUTPATIENT GOUT MANAGEMENT IN A MALAYSIAN TERTIARY RHEUMATOLOGY CENTRE}

M. H. Mustapha ${ }^{1}$, H. Baharuddin ${ }^{2}$, N. Zainudin ${ }^{1}$, S. S. Ch'ng ${ }^{1}$, H. Mohd Yusoof ${ }^{1}$, I. S. Lau ${ }^{1}$, M. Mohd Zain ${ }^{1}$, A. Rosman ${ }^{1} .{ }^{1}$ Hospital Selayang, Rheumatology Unit, Department of Medicine, Selangor, Malaysia; ${ }^{2}$ Universiti Teknologi MARA (UiTM), Faculty of Medicine, Hospital Selayang, Selangor, Malaysia

Background: Gout is one of the most common inflammatory arthropathies. A target serum uric acid of less than $300 \mu \mathrm{mol} / \mathrm{l}$ is recommended when tophi are present, and less than $360 \mu \mathrm{mol} / \mathrm{l}$ for non-tophaceous gout. Urate-lowering therapy (ULT) should be titrated until the target is achieved and long-term maintenance of the target concentration is recommended. Although ULT has been proven to reduce the uric acid level, less than half of treated patients achieved the target serum uric acid (sUA) in real-world clinical practice.

Objectives: To assess the mean treat-to-target achievement in outpatient management of gout by the tertiary rheumatology centre and to identify factors influencing the success rate.

Methods: Retrospective cross-sectional study of all patients with gout attending out-patient clinics in a rheumatology referral centre from $1^{\text {st }}$ January 2018 until $31^{\text {st }}$ December 2018. Electronic medical records were reviewed. The successful target achievement is defined as mean of all available sUA in 2018 which is $\leq 360$ and $\leq 300 \mu \mathrm{mol} / \mathrm{l}$ for non-tophaceous and tophaceous gout respectively. Chronic kidney disease (CKD) is defined as glomerular filtration rate of less than $60 \mathrm{ml} / \mathrm{min}$

Results: There were 251 patients analysed with mean age of $56.3 \pm 13.8$ years and disease duration of $10.5 \pm 9.2$ years. Majority were males $(215,85.7 \%)$ and $133(53 \%)$ patients had tophaceous gout. The rate of success achieving the target SUA level of $\leq 360$ and $\leq 300 \mu \mathrm{mol} / \mathrm{l}$ were $33.9 \%(40)$ and $15.8 \%(21)$ in non-tophaceous and tophaceous gout respectively. However, in patients who are compliant, the target sUA achieved is $52.4 \%$ (33) and $31.7 \%$ (19) in non-tophaceous and tophaceous gout respectively. Characteristics of patients who achieved the targeted sUA were patients of more than 50 years old $(48,78.7 \%)$, without family history of gout (29, $65.9 \%$ ), were prescribed colchicine prophylaxis upon initiating ULT $(46,76.7 \%)$, with absence of joint erosions (34,73.9\%) and those with normal creatinine clearance (40, $65.5 \%$ ). There were 120 (48.4\%) patients who were compliant to ULT. In 42 compliant patients who achieved target SUA, the mean allopurinol dose is $289.66 \mathrm{mg} \pm 101.2$ and $369.23 \mathrm{mg} \pm 175$ in non-tophaceous and tophaceous gout respectively. Sub-analysis in 31 compliant CKD patients, revealed no difference in allopurinol dose between those who achieved versus non-achieved target SUA (mean 243mg versus $263 \mathrm{mg}$ respectively). However, we noted that 11 (61\%) CKD patients with tophi did not achieved target sUA at dose less than $300 \mathrm{mg}$ allopurinol. Lower achievement of target sUA was significantly associated with presence of tophi $(p=0.001)$, poor compliance $(p=0.000)$ and presence of more than one comorbidity $(p=0.041)$.

Conclusion: There are several challenges in achieving target uric acid level contributed by both patient and clinician factors such as compliance, presence of comorbidity and ULT dose. Our study suggests that higher dosage of allopurino is required in patients with tophaceous gout, with or without renal impairment. However, the limitation of this study is, the small number of subjects which therefore needs further investigation.

References:

[1] Roddy, E., Packham, J., Obrenovic, K., Rivett, A., \& Ledingham, J. M. (2018) Management of gout by UK rheumatologists: a British Society for Rheumatology national audit. Rheumatology, 57(5), 826-830.

[2] Katayama A, Yokokawa $\mathrm{H}$, Fukuda $\mathrm{H}$, et al. Achievement of Target Serum Uric Acid Levels and Factors Associated with Therapeutic Failure among Japanese Men Treated for Hyperuricemia/Gout. Intern Med. 2019;58(9):1225-1231.

Disclosure of Interests: Mariam Hamid Mustapha: None declared, Hazlyna Baharuddin Speakers bureau: Sanofi, J\&J, Norliza Zainudin: None declared, Shereen Suyin Ch'ng Speakers bureau: Novartis, Pfizer, GSK, Habibah Mohd Yusoof: None declared, Ing Soo Lau: None declared, Mollyza Mohd Zain: None declared, Azmillah Rosman: None declared

DOI: 10.1136/annrheumdis-2020-eular.5823

\section{AB0933 PHYSICAL ACTIVITY DECREASES PAIN AND INFLAMMATION IN GOUT PATIENTS}

N. Schlesinger ${ }^{1}$, K. Jablonski ${ }^{2}$, E. Schwarz ${ }^{2}$, N. Young ${ }^{2} .{ }^{1}$ Rutgers Robert Wood Johnson Medical School, Medicine, New Brunswick, New Jersey, United States of America; ${ }^{2}$ The Ohio State University Wexner Medical Center, Medicine, Columbus, Ohio, United States of America

Background: Despite the high prevalence of gout, there has been little investigation into the relationship between physical activity and gout.

Objectives: To investigate whether physically active gout patients, as assessed by the International Physical Activity Questionnaire (IPAQ) long form, have lowe pain scores, decreased inflammation, assessed by $\mathrm{C}$-reactive protein (CRP) levels and less flares.

Methods: During scheduled appointments, gout patients not experiencing a flare at the time of visit were recruited from our clinics and consented to participate in the study. IPAQ were completed. Clinical data collected during the visit included age, years since diagnosis, flares per year, perceived pain at the time of visit and in the past 4 weeks, and C-reactive protein (CRP) levels.

Results: Thirty gout patients were recruited. Ages 31-86 (mean 61); duration of gout: one- 43 years (mean 9). IPAQ, separated gout patients into phys ically active $(n=16)$ and physically inactive cohorts $(n=14)(p<0.001$. Physically active gout patients had over 12 -fold fewer gout flares per year $(p<0.01)$ 10 -fold less CRP ( $p<0.01$, a 4.6-fold decrease in perceived pain at the time of visit $(p<0.01)$, and a 2.8 -fold decrease in perceived pain over the past 4-week period $(p<0.05)$

Conclusion: This is the first study using a validated physical activity tool, IPAQ, to assess physical activity in gout patients. In this study, physically active gout patients were found to have lower CRP levels, less flares per year, and decreased pain perception compared to those that are not physically active, highlighting, the importance of incorporating physical activity as a possible adjunct treatment option during intervals between flares. 
References:

[1] Benatti FB, Pedersen BK. Exercise as an anti-inflammatory therapy for rheumatic diseases-myokine regulation. Nat Rev Rheumatol 2015;11:86-97.

[2] Hagströmer M, Oja P, Sjöström M. The International Physical Activity Questionnaire (IPAQ): a study of concurrent and construct validity. Public Health Nutr 2006;9:755-62.

[3] Young NA, Jablonski K, Sharma J, Thomas E, Snoad B, Hampton J, et al. Low and Moderate Intensity Exercise Suppresses Inflammatory Responses in an Acute Mouse Model of Gout and Suggests Therapeutic Efficacy [abstract]. Arthritis Rheumatol. 2017;69 (suppl 10).

Disclosure of Interests: Naomi Schlesinger Grant/research support from: Pfizer, AMGEN, Consultant of: Novartis, Horizon Pharma, Selecta Biosciences, Olatec, IFM Therapeutics, Mallinckrodt Pharmaceuticals, Speakers bureau: Takeda, Horizon, Kyle jablonski: None declared, Emmy schwarz: None declared, Nicholas Young: None declared

DOI: 10.1136/annrheumdis-2020-eular.490

\section{AB0934 DUAL-ENERGY COMPUTED TOMOGRAPHY IN GOUT PATIENTS: IS IT USEFUL IN GENERAL PRACTICE?}

Y. Sherman ${ }^{1}$, P. Lipsky ${ }^{2}$, M. Bramwit ${ }^{1}$, N. Schlesinger ${ }^{1} .{ }^{1}$ Rutgers Robert Wood Johnson Medical School, New Brunswick, United States of America; ${ }^{2}$ RILITE Research Institute, Charlottesville, VA, United States of America

Background: Dual-Energy CT (DECT) has high sensitivity and specificity for detecting monosodium urate (MSU) crystal deposition. Although widely used in research, few studies have evaluated the usefulness of DECT in clinical practice. Objectives: To evaluate the use of DECT in a clinical setting and determine its utility

Methods: We retrospectively evaluated the records of all patients referred for DECT scans over a 6.5-year period. Patient charts were reviewed for clinical features.

Results: 113 patients (17.5/yr) received DECT evaluation at a university hospital over the study period (234 scans). All were referred by rheumatologists. Medical records were available for 69 patients (134 scans), including 44 males and 25 females (mean age 62 (SD, 12.9, range: 34-85 yrs). Mean duration of gout was 6.7 (SD, 8.1) yrs. DECT was ordered to evaluate known gout $(36 / 69,52.1 \%)$, suspected gout $(32 / 69,46.4 \%)$, and suspected calcium pyrophosphate (CPP) disease (1/69, 1.4\%). 32/69 (46.4\%) of patients were on urate-lowering therapy. $61 \%$ (42/69) had MSU crystal and none had CPP deposition. Mean MSU volume was 1.6cc (SD, 5.2cc; range: $0.01-35 \mathrm{cc}$.) The joints imaged were feet/ankles $(80 / 134,60 \%)$ and hands/wrists $(53 / 134,40 \%) .23 / 33(69.7 \%)$ patients with DECT positivity had elevated serum urate (SU) levels $>6 \mathrm{mg} / \mathrm{dL}$; however, elevated SU was not significantly associated with DECT positivity (odds ratio (OR) $1.9,95 \% \mathrm{Cl}: 0.59-5.95, \mathrm{p}=0.28$ )

For patients with positive scans, mean gout duration from first known flare was 9.5 (SD, 8.8) yrs.

Among patients who had scans completed within $1 \mathrm{yr}$ of the first known gout flare, $1 / 10$ were positive (10\%); $4 / 16$ within $2 \mathrm{yrs}(25 \%)$; and $8 / 21$ within $3 \mathrm{yrs}$ $(29.6 \%)$.

Of patients with positive DECT scans, $24 / 42(57 \%)$ had symmetric distribution of MSU crystal deposition: 10/24 (42\%) hands and 14/24 (58\%) feet; with gout duration of 7.9 (SD, 8.0) yrs.

Conclusion: DECT was infrequently utilized and only by rheumatologists. Only $60 \%$ of patients referred for DECT scanning because of known or suspected gout had MSU deposition. DECT was uncommonly positive in patients with a 1-3 yr history of gout. When positive, the MSU crystal deposition was symmetrical in most gout patients. DECT scans, while important in furthering our understanding of gout biology, are not routinely used in general practice and often do not provide important decision support information. Establishment of practice guidelines might be important in developing more appropriate utilization of DECT.

Disclosure of Interests: Yekaterina Sherman: None declared, Peter Lipsky Consultant of: Horizon Therapeutics, Mark Bramwit: None declared, Naomi Schlesinger Grant/research support from: Pfizer, AMGEN, Consultant of: Novartis, Horizon Pharma, Selecta Biosciences, Olatec, IFM Therapeutics, Mallinckrodt Pharmaceuticals, Speakers bureau: Takeda, Horizon

DOI: 10.1136/annrheumdis-2020-eular.3833

\section{AB0935 \\ HYDROLYSIS OF INORGANIC PYROPHOSPHATE IN HUMAN SYNOVIAL FLUID BY IMMOBILIZED PYROPHOSPHATASES}

A. Valueva ${ }^{1}$, R. Romanov ${ }^{2}$, S. Mariasina ${ }^{2}$, M. Eliseev ${ }^{3}$, E. Rodina ${ }^{2} .{ }^{1}$ Pavlov Ryazan State Medical University, Ryazan, Russian Federation; ${ }^{2}$ Lomonosov Moscow State University, Moscow, Russian Federation; ${ }^{3}$ V.A.Nasonova Research Institute of Reumatology, Moscow, Russian Federation
Background: Calcium pyrophosphate deposition (CPPD) disease, alternatively known as pseudogout, is a type of arthropathy caused by a deposition of microcrystals of calcium pyrophosphate (CaPPi) in joint tissues, particularly in fibrocartilage and hyaline cartilage. Up to date, specific treatment of CPPD disease has not been developed. Conventional therapy is focused on anti-inflammatory and immunosuppressive treatment aimed at the prevention of acute symptoms. Previously we suggested for this purpose inorganic pyrophosphatases (PPases) immobilized on nanodiamonds of detonation synthesis (NDs) [1]. We synthesized and characterized conjugates of NDs with PPases from Escherichia coli and Mycobacterium tuberculosis (Ec-PPase or Mt-PPase) using amino-substituted NDs with (ND-L) or without linker (ND-NH N $_{2}$. The conjugates showed high enzymatic activity in the in vitro model system simulating the ionic composition of synovial fluid

Objectives: The present work is focused on testing enzyme-based agents for the partial dissolution of calcium pyrophosphate deposits in the synovial fluid of patients with CPPD disease.

Methods: PPase activity of soluble and immobilized PPases was evaluated as the rate of PPi decrease with time. $1 \mathrm{mM} \mathrm{PP}$, was added to the synovial fluid of patients with CPPD containing the samples of PPases, and the amount of PP in the samples was determined every $2-4$ hours using ${ }^{31} \mathrm{P}$ NMR spectroscopy. Results: We demonstrated the possibility of differential detection of pyrophosphate $(\mathrm{PP})$ among the spectrum of phosphorus-containing compounds in the synovial fluid and used the rate of decrease of exogenous PP. to estimate hydroIytic activity of PPases and PPase-based conjugates. The hydrolysis followed the first order reaction kinetics and the rate constants by different samples of PPases are presented in Table 1. Non-enzymatic hydrolysis of exogenous PP was quite moderate or not observed at all. Ec-PPase (both soluble and immobilized) showed very low hydrolytic activity with the residual PP, levels above $80 \%$. However, all samples of Mt-PPase showed significant hydrolytic activity. In two cases of three, PP was almost completely hydrolyzed within 20 hours. The maximum activity $\left(2.24{\left.\mathrm{U} \cdot \mathrm{mg}^{-1}\right)}^{-1}\right.$ was shown by Mt-PPase immobilized on ND-L. Hydrolytic activity for all studied enzymes is only $1-2 \%$ of such values under optimal in vitro conditions, most probably due to the inhibiting effect of calcium in synovial fluid. Nevertheless, the activity of Mt-PPase-based samples was comparable with the values typical for some classes of hydrolases. It allows us to consider the suggested PPase-based materials as promising agents for the hydrolysis of $\mathrm{PP}_{\mathrm{i}}$ in the joint tissues in vivo.

Table 1. PP, hydrolysis in the synovial fluid by soluble or immobilized PPases.

\begin{tabular}{lccc}
\hline Samples & & $k, \mathrm{hr}^{-1}$ & $A, \mathrm{U} \cdot \mathrm{mg}^{-1}$ \\
\hline Control & - & $0.010 \pm 0.001$ & 0 \\
\hline & $\mathrm{ND}^{-N}{ }_{2}$ & 0 & 0 \\
Ec-PPase & ND-L & $0.013 \pm 0.002$ & 0 \\
& Soluble & $0.025 \pm 0.003$ & $0.33 \pm 0.04$ \\
Mt-PPase & Immobilized on ND-NH $_{2}$ & 0 & 0 \\
& Immobilized on ND-L $^{2}$ & $0.017 \pm 0.003$ & $0.22 \pm 0.04$ \\
& Soluble & $0.10 \pm 0.01$ & $1.3 \pm 0.1$ \\
& Immobilized on ND-NH & $0.04 \pm 0.01$ & $0.53 \pm 0.05$ \\
& Immobilized on ND-L & $0.17 \pm 0.02$ & $2.2 \pm 0.3$ \\
\hline
\end{tabular}

Conclusion: In this work, we applied the ${ }^{31} \mathrm{P}$ NMR spectroscopy to estimate the quantity of $P$ and $P P$ in synovial fluids of patients with CPPD disease. The conjugates of bacterial PPases with detonation nanodiamond were demonstrated to retain enzymatic activity in the hydrolysis of exogenous $\mathrm{PP}$ in human synovia fluid. These results provide the basis for the further tests of PPase-based conjugates on animal models in vivo.

References:

[1] Rodina E.V., Valueva A.V., Yakovlev R.Y., Vorobyeva N.N., Kulakova I.I. Lisichkin G.V., Leonidov N.B. Immobilization of inorganic pyrophosphatase on nanodiamond particles retaining its high enzymatic activity // Biointerphases, Vol. 10, No. 4, 2015. P. 041005.

Disclosure of Interests: Anastasiya Valueva: None declared, Roman Romanov: None declared, Sofia Mariasina: None declared, Maxim Eliseev Speakers bureau: Novartis, Menarini Group, Alium, Elena Rodina: None declared DOI: 10.1136/annrheumdis-2020-eular.5321

AB0936

CLINICAL STUDY ON PERIPHERAL BLOOD IMMUNE FUNCTION IN PATIENTS WITH GOUTY ARTHRITIS

H. Wang ${ }^{1}, \mathrm{H}$. Gao ${ }^{1} .{ }^{1}$ The Second Hospital of Shanxi Medical University, Rheumatology, Taiyuan, China

Background: Gout is an inflammatory disease characterized by hyperuricemia and recurrent arthritis. In severe cases, joint disability and renal insufficiency may occur ${ }^{[1]}$. In recent years, many studies have found that immune dysfunction plays an important role in the occurrence and development of gout ${ }^{[2]}$. Therefore, 